\title{
A study on preparation and mechanical properties of long jute fiber reinforced polylactic acid by the injection molding process
}

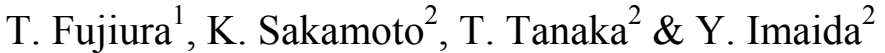 \\ ${ }^{1}$ Mechanical Engineering Research Laboratory, Kobe Steel, LTD., Japan \\ ${ }^{2}$ Faculty of Engineering, \\ Department of Mechanical and Systems Engineering, \\ Doshisha University, Japan
}

\begin{abstract}
Natural plant fibers have recently attracted attention as reinforcements for plastics due to their high specific mechanical properties and carbon neutrality. This study explored the preparation process for long jute fiber reinforced polylactic acid (LJF/PLA) pellets for injection molding and the mechanical performance of the molded composites. The originally fabricated pultrusion process for manufacturing long fiber reinforced thermoplastic (LFT) was capable of preparing LJF/PLA pellets, with the excellent impregnation of resin into jute fiber bundles. The incorporation of jute fibers of 50 mass $\%$ into PLA resulted in the improvement of flexural strength and modulus of injection molded composites. On the other hand, jute reinforcement was not effective for increasing the impact strength of the composite. Moreover, this study also investigated the influence of the moisture that had remained in jute fibers on the mechanical properties of the LJF/PLA composites. As the moisture content of jute fiber increased, the average molecular weight of matrix PLA in the LJF/PLA lowered due to the hydrolysis, and consequently the mechanical properties of the composites decreased. Eliminating moisture from jute fibers in the preparation process of LJF/PLA pellets was found to be important for preventing the deterioration in the molecular weight of PLA and the properties of the molded composites.
\end{abstract}

Keywords: polylactic acid (PLA), natural plant fibers, jute, long-fiber reinforced thermoplastic (LFT), moisture content, molecular weight, mechanical properties. 


\section{Introduction}

In recent years, thermoplastics reinforced with natural plant fibers (NFRTP) have been gaining considerable attention for their potential contribution to improve environmental issues, mainly on reduction of carbon dioxide $\left(\mathrm{CO}_{2}\right)$ emissions and the saving of fossil resources. NFRTP have also been attracting interest and have been widely applied in the industrial fields due to their high mechanical properties, low cost and desirable recycling features [1-4].

Green composites, consisting of polymers from natural resources and natural plant fibers (NF), are promisingly noticed as more 'sustainable' material. Among many kinds of natural-resourced polymers, polylactic acid (PLA) is most popular for the matrix of green composites and many researches on PLA-based composites reinforced with NF, such as jute, kenaf and hemp, have been carried out expecting to enhance the mechanical and thermal properties and of PLA [5-7]. While having excellent moldability and mechanical properties, PLA has a problem with degradability during processing of NF reinforced composites. PLA can easily hydrolyse at high temperatures by the reaction with the moisture that is contained in NF as adsorbed water at possibly as much as $10 \%$ in weight. Therefore, the control of moisture of the compound in the molding process would be a key issue to prevent the decomposition of PLA and to ensure the mechanical performance of the composites.

In this study, LJF/PLA pellets with various moisture contents have been prepared by an originally fabricated process for manufacturing LFT. The mechanical properties of injection molded LJF/PLA composites have been examined from a viewpoint of clarifying the influence of the moisture content of pellets on the average molecular weight of the matrix PLA and mechanical properties of the composites. We have also investigated the effect of the annealing of the composites and the effect of air-plasma treatment on starting jute fibers on mechanical properties of the LJF/PLA composites.

\section{Experimental}

\subsection{Materials}

The matrix polymer used is polylactic acid LACEA H-100J (Mitsui Chemicals, Inc.). Bleached spun jute yarn (Tesac Corporation, yarn count:16.5) was used as the reinforcement fiber. The filament diameter of jute is about 20-100 $\mu \mathrm{m}$.

\subsection{Preparation of LJF/PLA pellets}

LJF/PLA compounds for injection molding were prepared as LFT pellets using an originally developed LFT production process. The schematic diagram of the production apparatus is shown in Figure 1. Jute yarns were induced continuously through the pre-heater for drying and then into the cross head die for impregnating molten PLA resin, which was supplied from the screw extruder. The composite strand of jute/PLA was pulled out from the die, followed by 
cooling with water or air-blow and cut into pellets in a fixed length. In addition to these general pultrusion techniques for thermoplastics, the apparatus is equipped with a novel function to twist the pultruded strand continuously at optional angles, which can contribute to reducing the pultruding force and to attain excellent resin impregnation between fiber filaments.

Figure 2 shows the schematic image of the LFT pellet derived by this original process. In the axial direction of the pellet, fiber tows are spirally incorporated in the matrix resin.

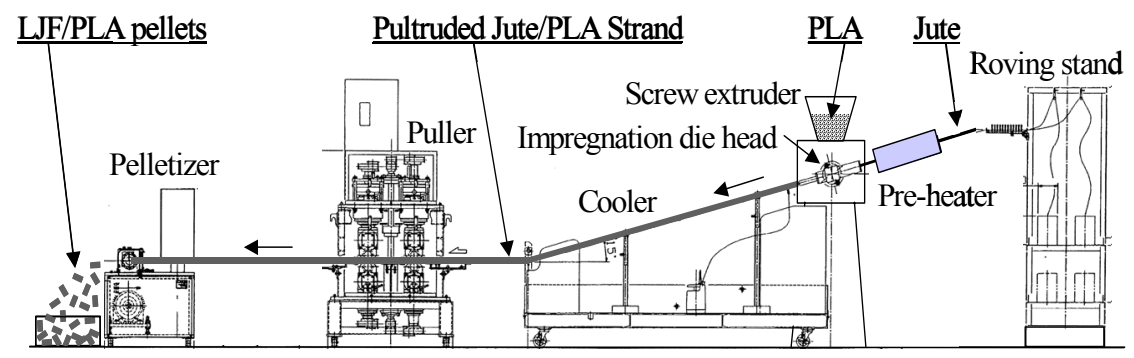

Figure 1: $\quad$ The schematic diagram of the LFT production apparatus.

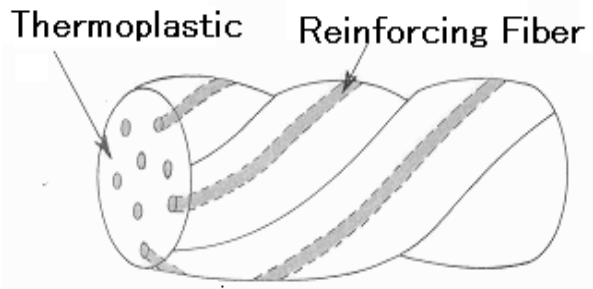

Figure 2: $\quad$ The schematic drawing of the LFT pellet.

Table 1 describes the varied parameters for preparing LJF/PLA pellets. In most cases, jute was treated with air-plasma aiming to improve interfacial adhesion between jute and PLA, expecting higher mechanical performance of the final composites. The treatment was done on-site of pultrusion using an air plasma machine (KASUGA ELECTRIC WORKS LTD.) with the power of 50 $\mathrm{kW}$ in corona discharge.

In some cases in which the LJF/PLA pultruded strands were cooled with water by showering or dipping, pellets obtained were subsequently dried at $80^{\circ} \mathrm{C}$ for at least 24 hours before they were used in injection molding. All kinds of $\mathrm{LJF} / \mathrm{PLA}$ pellets were prepared in $6 \mathrm{~mm}$ lengths at $50 \mathrm{wt} \%$ of jute content.

\subsection{Molding of LJF/PLA composites}

LJF/PLA pellets were then injection molded into tensile, flexural and izod impact specimens using an injection molding machine IS-100EN (Toshiba 
Machine Co.). The injection process was carried out with the cylinder temperature at $160^{\circ} \mathrm{C}$ and the mold temperature at $25^{\circ} \mathrm{C}$. As the reference sample, specimens of non-reinforced PLA were also prepared in the same manner.

Table 1: $\quad$ Preparing conditions for LJF/PLA pellets.

\begin{tabular}{ccccc}
\hline $\begin{array}{c}\text { Sample } \\
\text { ID }\end{array}$ & $\begin{array}{c}\text { Air-plasma } \\
\text { treatment on } \\
\text { jute fibers }\end{array}$ & $\begin{array}{c}\text { Cooling methods of } \\
\text { LJF/PLA strand }\end{array}$ & $\begin{array}{c}\text { Putruding } \\
\text { speed } \\
{[\mathrm{m} / \mathrm{min} .]}\end{array}$ & $\begin{array}{c}\text { Drying } \\
\text { Conditions of } \\
\text { LJF/PLA Pellets }\end{array}$ \\
\hline \hline LJF/PLA-1 & ON & Dipping in water bath & 20 & $80^{\circ} \mathrm{C} \times 24 \mathrm{hr}$ \\
\hline LJF/PLA-2 & ON & Dipping in water bath & 20 & - \\
\hline LJF/PLA-3 & OFF & Dipping in water bath & 20 & $80^{\circ} \mathrm{C} \times 25 \mathrm{hr}$ \\
\hline LJF/PLA-4 & ON & Showering water mist & 20 & $80^{\circ} \mathrm{C} \times 25 \mathrm{hr}$ \\
\hline LJF/PLA-5 & ON & Showering water mist & 20 & - \\
\hline LJF/PLA-6 & ON & Air-blowing & 10 & - \\
\hline LJF/PLA-7 & OFF & Air-blowing & 10 & - \\
\hline PLA & - & - & - & $80^{\circ} \mathrm{C} \times 24 \mathrm{hr}$ \\
\hline
\end{tabular}

\subsection{Evaluation of LJF/PLA composites}

Evaluation of the mechanical properties was carried out on as-molded specimens and the specimens were heat-treated at $80^{\circ} \mathrm{C}$ for 8 hours subsequent to injection molding, to clarify the effect of annealing on mechanical properties. Tensile tests were performed out according to JIS K7113 using an Autograph (Shimadzu Corporation) with the crosshead speed at $1.0 \mathrm{~mm} / \mathrm{min}$. Flexural tests were carried out according to JIS K6911 also using an Autograph with the distance between fixed points at $150 \mathrm{~mm}$ and crosshead speed at $10 \mathrm{~mm} / \mathrm{min}$. Notched-Izod impact tests were carried out according to JIS K7062.

Average molecular weights of PLA in the injection-molded samples were determined using the gel permeation chromatography (GPC) based on polystyrene standards. The analyzing system used was Waters-600 high-pressure pump equipped with Shodex GPC column LF-804 and the differential refractive index detector SE-71 (Showa Denko, Co.). GPC separation was operated using chloroform as the carrier eluent at the flow rate of $1.0 \mathrm{ml} / \mathrm{min}$, with the column temperature at $40^{\circ} \mathrm{C}$.

\section{Results and discussion}

\subsection{Characteristics of LJF/PLA pellets}

The appearance of LJF/PLA pellets is shown in Figure 3. The fact that pellets are shown almost white color, which is originated from starting with bleached jute and the PLA matrix, suggests that discoloration or damage of jute fibers by heat 
rarely occurred during the pellet processing. Figure 4 shows a typical SEM image of a cross sectional view of the LJF/PLA pellet. It is clearly found that the matrix PLA was well impregnated between the jute filaments and almost no air voids were observed.

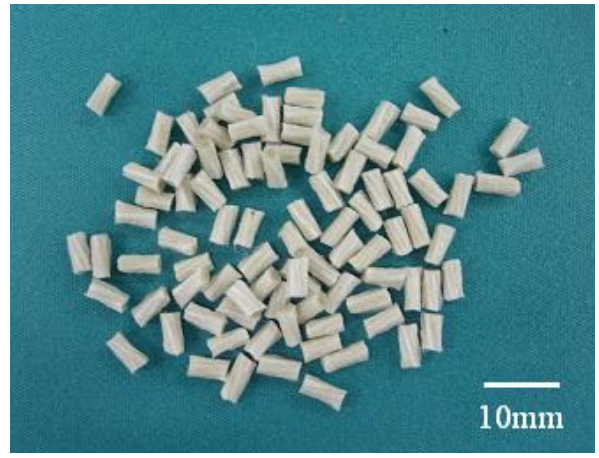

Figure 3: $\quad$ The appearance of LJF/PLA pellets.

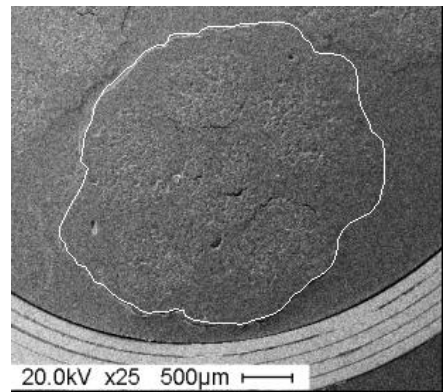

(a) A whole cross section (Lower magnification)

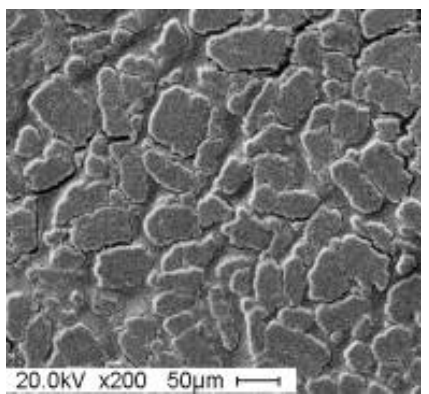

(b) A minute observation (Higher magnification)

Figure 4: Typical SEM image of cross sectional view of the LJF/PLA pellet.

\subsection{Mechanical properties of LJF/PLA composites}

Table 2 shows tensile strength, flexural strength and Izod impact strength of as-molded LJF/PLA specimens and specimens annealed at $80^{\circ} \mathrm{C}$ for 8 hours, with each property of non-reinforced PLA, as well as the moisture contents of LJF/PLA pellets measured prior to the injection molding. The LJF/PLA-4 asmolded specimen, the origin pellets of which contained the least moisture among all samples, showed the highest mechanical properties. Figure 5 shows the example of the tensile stress-strain curves of the LJF/PLA-4 as-molded specimen and the non-reinforced PLA specimen. The tensile strength of the LJF/PLA-4 as-molded specimen is 1.4 times larger than that of non-reinforced PLA. The tensile modulus also increased 2.2 times, whereas the tensile strain reduced by 
reinforcing PLA with jute. As shown in Table 2, the LJF/PLA-4 as-molded specimen also exhibited higher flexural strength and izod impact strength than non-reinforced PLA. Reinforcement with jute fibers by this LFT-injection molding process can be effective for the improvement of the mechanical properties of PLA.

Table 2: $\quad$ Mechanical properties of LJF/PLA.

\begin{tabular}{cccccccc}
\hline \multirow{2}{*}{$\begin{array}{c}\text { Sample } \\
\text { ID }\end{array}$} & $\begin{array}{c}\text { Moisture contents } \\
\text { of LJF/PLA pellets } \\
{[\%]}\end{array}$ & \multicolumn{2}{c}{$\begin{array}{c}\text { Tensile strength } \\
{[\mathrm{MPa}]}\end{array}$} & $\begin{array}{c}\text { Flexural strength } \\
{[\mathrm{MPa}]}\end{array}$ & \multicolumn{2}{c}{$\begin{array}{c}\text { Izod impact } \\
{\left[\mathrm{kJ} / \mathrm{m}^{2}\right]}\end{array}$} \\
\cline { 3 - 8 } & As-molded & Annealed & As-molded & Annealed & As-molded & Annealed \\
\hline \hline LJF/PLA-1 & 0.828 & 58.0 & 33.7 & 97.7 & 68.5 & 2.31 & 2.73 \\
\hline LJF/PLA-2 & 6.157 & 20.0 & 8.2 & 39.3 & 25.0 & 1.97 & 1.65 \\
\hline LJF/PLA-3 & 0.894 & 50.3 & 32.7 & 83.5 & 56.2 & 2.07 & 2.06 \\
\hline LJF/PLA-4 & 0.646 & 62.2 & 39.3 & 98.8 & 76.4 & 2.21 & 1.93 \\
\hline LJF/PLA-5 & 2.097 & 23.9 & 18.1 & 54.3 & 35.8 & 1.92 & 1.72 \\
\hline LJF/PLA-6 & 1.300 & 35.7 & 16.8 & 69.3 & 43.1 & 1.77 & 1.98 \\
\hline LJF/PLA-7 & 1.125 & 49.6 & 20.5 & 82.1 & 49.0 & 2.17 & 1.90 \\
\hline PLA & 0.080 & 42.9 & - & 67.6 & - & 1.78 & - \\
\hline
\end{tabular}

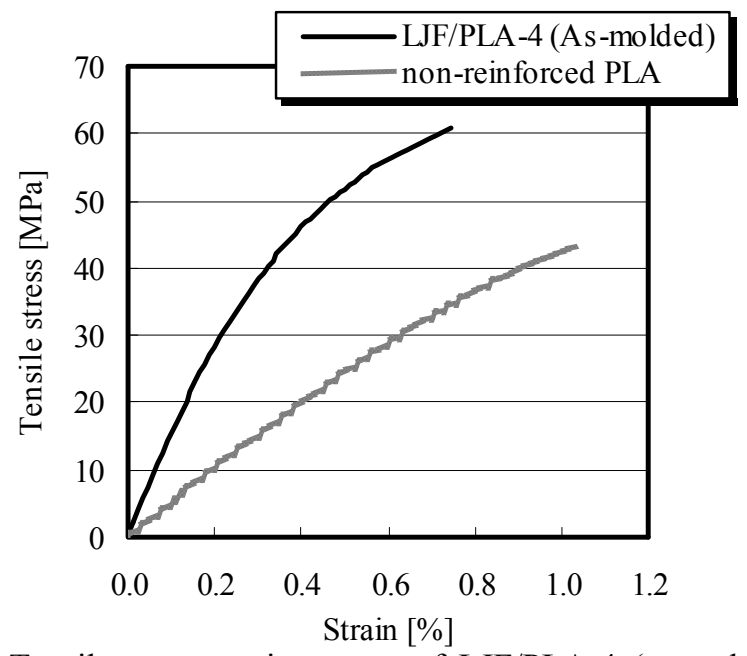

Figure 5: Tensile stress-strain curves of LJF/PLA-4 (as-molded) and nonreinforced PLA.

\subsection{Effect of the annealing of LJF/PLA composites on mechanical properties}

Tensile, flexural and izod impact strengths of LJF/PLA composites annealed at $80^{\circ} \mathrm{C}$ for 8 hours are also described in Table 2 , contrastively to those of as-molded composites without annealing. In most cases, those properties of LJF/PLA composites markedly decreased after they were annealed. For example, 
the tensile strength of LJF/PLA-4 dropped about $37 \%$ from $62.2 \mathrm{MPa}$ down to $39.3 \mathrm{MPa}$. Figure 6 compares the SEM images of the fracture surface of as-molded and annealed LJF/PLA-4 specimens in the tensile test. The adhesion between jute and the PLA matrix in the as-molded specimen seems excellent, while fiber pullouts or a little sticking of the matrix resin onto the fiber surface, indicating the poor interfacial adhesion, can be found in the annealed specimen. This observation result suggests that the bonding between jute and PLA became worse by annealing and consequently the poorer stress transfer at fiber/matrix interface caused the decrease in strengths of the composites. As one of the reasons for the deterioration of interfacial adhesion, it is supposed that hydrolysis of PLA sticking to or in the vicinity of the jute filaments occurred by the reaction with the moisture which remained in jute fibers during the course of annealing. Further study, such as minute evaluation on the degradation level of PLA at the interface or the exploration of the effect of heat treatment on the interfacial strength by direct measurement should still be necessary from the standpoint of the relation with the moisture content of jute fibers.

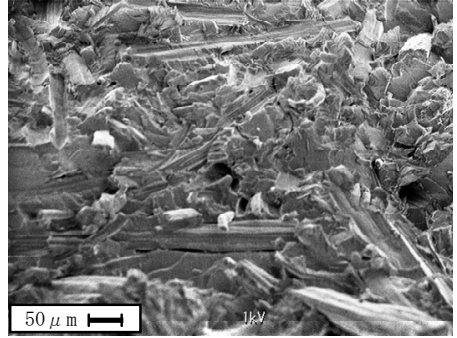

(a) As-molded

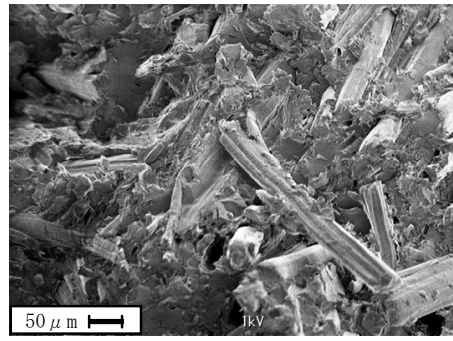

(b) Annealed

Figure 6: SEM photographs of the fracture surface of the LJF/PLA-4 specimen in the tensile test.

\subsection{Relationship between the molecular weight of the PLA matrix and the mechanical properties of LJF/PLA composites}

Figure 7 describes the average molecular weights of matrix PLA in injection molded LJF/PLA composites, in the correlation with the moisture content of corresponding raw LJF/PLA pellets. The molecular weights of PLA in the composites strongly depend on the moisture content of the originated pellets. Considering the result that the average molecular weight of the non-reinforced PLA specimen was about 60,000, it is obvious that PLA was decomposed into much lower molecular weights by the hydrolysis reaction with the moisture remaining in the jute fiber, in the course of the injection molding process. Figure 8 shows the relationship between the average molecular weights of the PLA matrix and the tensile strengths of the LJF/PLA composites. The tensile strengths of the composites are also apparently correlative with the molecular weight of the PLA matrix. Regarding Figures 7 and 8, moisture control in LJF/PLA pellets is essential to minimize the drop of mechanical properties of the 
composites. Assuming that the molecular weight of the PLA matrix of the composites can be preserved as high as that of non-reinforced PLA, better mechanical properties would be expected, as estimated with the dashed line in Figure 8 .

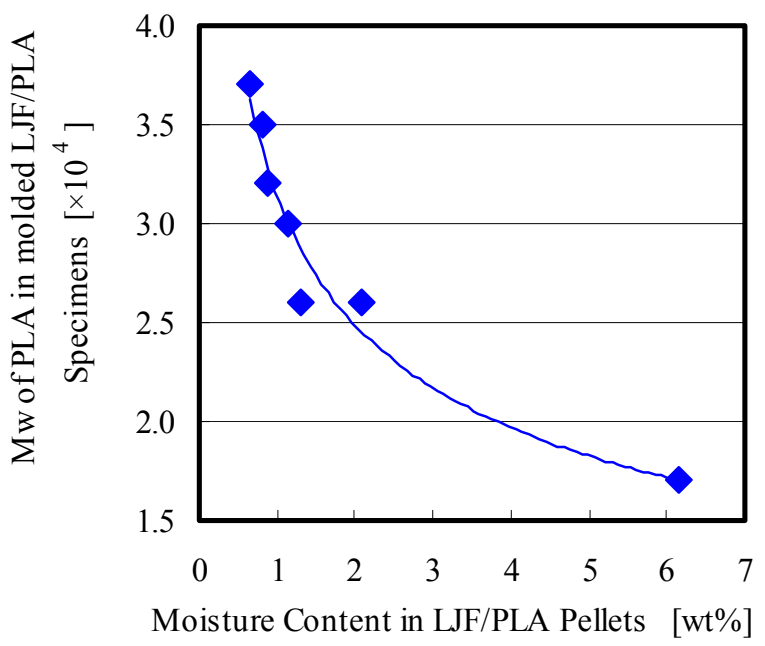

Figure 7: Relationship between the moisture contents in LJF/PLA pellets and the average molecular weights of PLA matrices in LJF/PLA specimens.

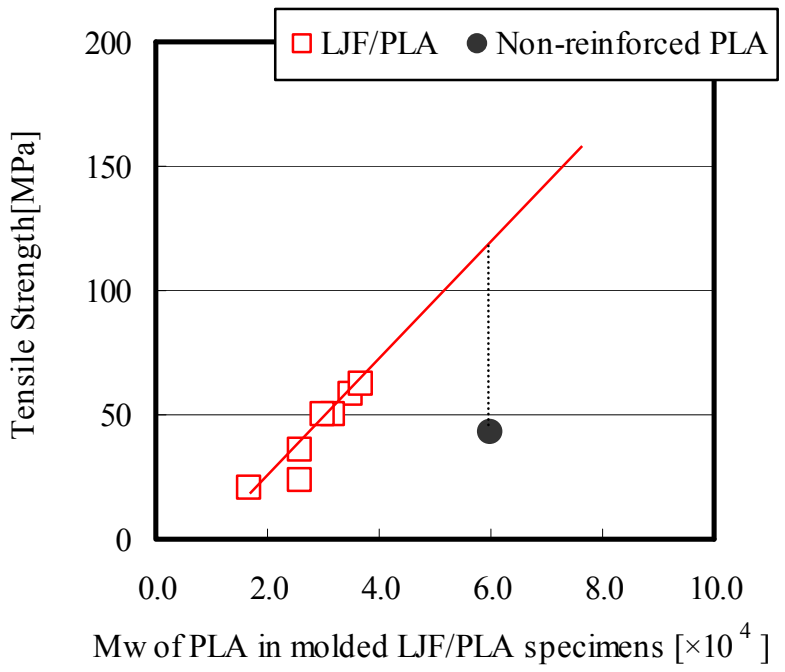

Figure 8: Relationship between the average molecular weights of PLA matrices and tensile strengths of LJF/PLA specimens. 


\subsection{Effect of air-plasma treatment of jute fibers on the mechanical properties of LJF/PLA composites}

Figure 9 describes the comparisons of tensile strength of the LJF/PLA specimens, which were molded with the composite pellets prepared by the pultrusion process with and without on-line air-plasma treatment of the jute. The strength had been expected to increase by air-plasma treatment due to the chemical modification of the surface of the jute, such as forming oxygencontaining functional groups, which would help to improve adhesion to the PLA matrix [8]. However, the effect of the air-plasma treatment was not evident here and no tendency can be observed in the order of tensile strength. Considering that the tensile strength of those specimens are dependent on the moisture content of raw LJF/PLA pellets shown in Table 2, it is suggested that the reduction in molecular weights of the PLA matrix by hydrolysis is rather dominant over the mechanical properties of the composites in this experiment.

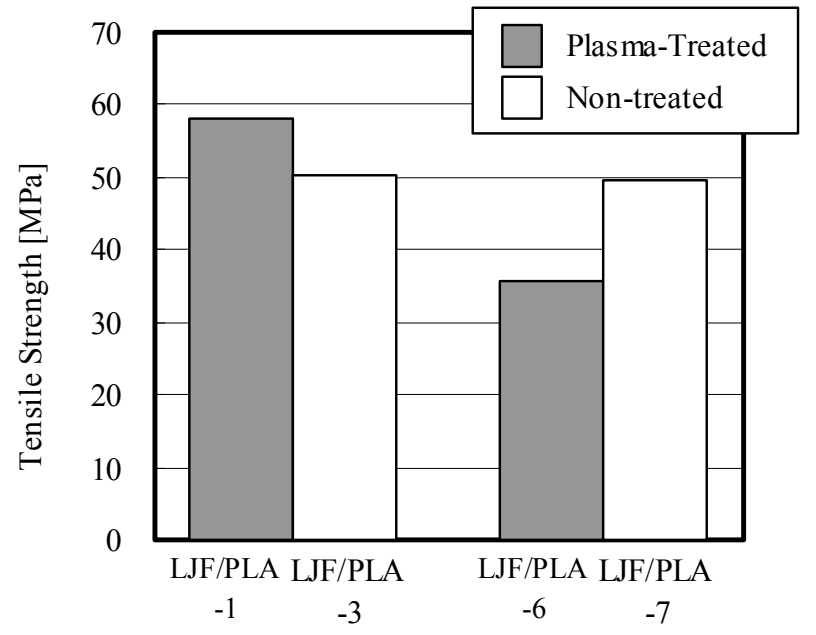

Figure 9: Comparison of the tensile strength of LJF/PLA composites prepared from jute with and without air-plasma treatment.

\section{Summary}

Long jute fiber reinforced PLA pellets were successfully prepared using an originally fabricated process for manufacturing LFT and the mechanical properties of injection molded LJF/PLA composites have been investigated. Summarized results and remarks are as follows.

(1) Reinforcement of jute fiber can contribute to the improvement of strength and modulus of PLA, whereas the strain of the composites became lower than that of non-reinforced PLA. 
(2) Annealing at $80^{\circ} \mathrm{C}$ reduced the mechanical properties of composites possibly because of the decline of interfacial adhesion between jute and matrix PLA arising from the hydrolysis reaction of PLA with the moisture remaining in jute.

(3) The average molecular weights of the PLA matrix in the composites depend on the moisture content of raw pellets examined prior to injection molding, and govern the mechanical properties of the composites.

\section{References}

[1] Nabi Saheb, D. \& Jog, J. P., Natural fiber polymer composites: A review. Advances in Polymer Technology, 18(4), pp. 351-363, 1999.

[2] Arzondo, L. M., Perez, C. J. \& Carella, J. M., Injection molding of long sisal fiber-reinforced polypropylene: Effects of compatibilizer concentration and viscosity on fiber adhesion and thermal degradation. Polymer Engineering and Science, 45, pp. 613-621, 2005.

[3] Shito, T., Okubo, K., \& Fujii, T., Development of eco-composites using natural bamboo fibers and their mechanical properties. High Performance Structures and Composites (HPSC2002), WIT press, pp. 175-182, 2002.

[4] Aichholzer, W., Natural fibre applications in automotive manufacturing. Proc. of $6^{\text {th }}$ Global Wood and Natural Fibre Composites Symposium, org. Institute fuer Werkstofftechnik Kunststoff- und Rycyclingtechnik, University of Kassel, pp. A11-1-A11-9, 2006.

[5] Takagi, H., Latest fiber reinforced plastics: Advanced application examples and future technologies. Environment-friendly FRP made from natural fiber reinforced materials. Engineering Materials, 54(4), pp. 51-54, 2006.

[6] Bogren, K. M, Gamstedt, E. K., Neagu, R. C., Aåkerholm, M. \& Lindstroöm, M., Dynamic-mechanical properties of wood-fiber reinforced polylactide: Experimental characterization and micromechanical modelling. Journal of Thermoplastic Composite Materials, (19)6, pp. 613-637, 2006.

[7] Ben, G., Kihara, Y. \& Aoki, Y., Optimum molding conditions for fabricating green composites composed of kenaf fibers and PLA resin. Proc. of the $4^{\text {th }}$ Int. Workshop on Green Composites, org. The Committee on Composite Materials, The Society of Materials Science, Japan, pp. 106-111, 2006.

[8] Morales, J., Olayo, M. G., Cruz, G. J., Herrera-Franco, P. \& Olayo, R., Plasma modification of cellulose fibers for composite materials. Journal of Applied Polymer Science, 101(6), pp. 3821-3828, 2006. 